\title{
Articles
}

\section{Facile Access to a Variety of 2,5-Biaryl-1,2,4-triazol-3-ones via Regioselective $N$-Arylation of Triazolones}

\author{
Jiyeon Park and Junghyun Chae* \\ Department of Chemistry and Institute of Basic Sciences, Sungshin Women's University, Seoul 136-742, Korea \\ ${ }^{*}$ E-mail: jchae@Sungshin.ac.kr \\ Received May 19, 2010, Accepted June 4, 2010
}

\begin{abstract}
A selective synthetic method of the 2,5-biaryltriazolones has been developed via copper-catalyzed $N$-arylation reaction. Aryltriazolones, which were readily prepared from commercially available compounds, were $N$-arylated to 2,5-biaryltriazolones with high regioselectivity. This approach allows for access to a variety of 2,5-biaryl-1,2,4-trizol-3-ones in a simple and practical manner.
\end{abstract}

Key Words: $N$-Arylation, Copper-catalyzed cross-coupling, $N$-Heterocycles, Regioselectivity, Triazolones

\section{Introduction}

Triazolone ring structure is often found in a number of biologically active compounds. ${ }^{1}$ Depending on the substituents at $\mathrm{N}-2, \mathrm{~N}-4$, and $\mathrm{C}-5$ positions of the triazolone ring, triazolones show various pharmaceutical activities such as antitumor, antiinflammatory, antifungal, PPARs agonistic, $\mathrm{NK}_{1}$-antagonistic activities. In particular, biaryltriazolones having different patterns of aryl substituents (2,5-biaryl-1,2,4-triazol-3-ones and 4,5-biaryl-1,2,4-triazol-3-ones) are currently being developed as Maxi-K channel opener ${ }^{2}$ and Hsp90 inhibitors. ${ }^{3}$ So far, a majority of biaryltriazolones have been prepared by late-stage ring cyclization. ${ }^{2,4}$ In this route, the installation of desired substituents at specific nitrogens is first carried out, and subsequent ring cyclization results in the substituted biaryltriazolones. However, tedious protection and deprotection steps are often unavoidable ${ }^{5}$ because of little reactivity differences of nitrogens in the linear intermediates, and harsh cyclization conditions for biaryl intermediates are also problematic especially when they are functionalized. In our efforts to synthesize the derivatives of 2,5-biaryl-1,2,4-triazol-3-ones for SAR study, we realized that the traditional stepwise synthetic methods hamper efficient production of a series of compounds in a short time. Therefore,

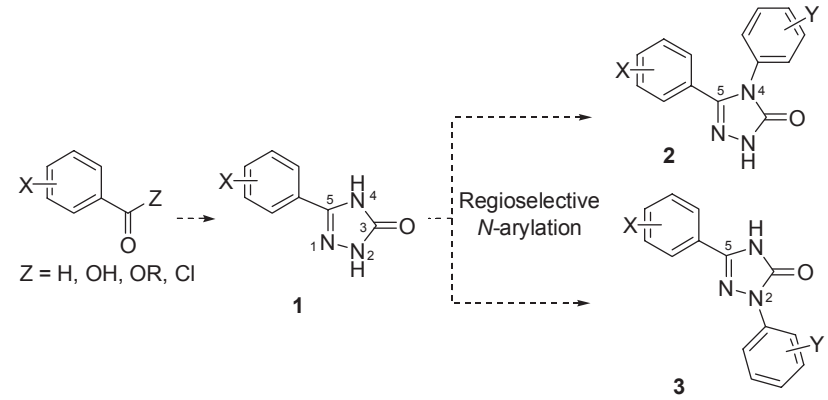

Scheme 1. Synthetic strategy for biaryltriazolones we proposed an efficient synthetic route to 2,5-biaryl-1,2,4triazol-3-ones as shown in Scheme 1. This scheme involves the synthesis of a common intermediate (1), in which two reactive nitrogen sites $(\mathrm{N}-2$ vs. N-4) are available. In order to obtain 2 and/or $\mathbf{3}$ in a selective manner, highly regioselective $N$-arylation must be developed. Herein, we report a highly selective route to a variety of 2,5-biaryl-1,2,4-triazol-3-ones via copper-catalyzed $N$-arylation.

\section{Results and Discussion}

Aryltriazolones (1), the common intermediates for various biaryltriazolones, can be synthesized in a straightforward way from commercially available starting compounds following the literature procedures (Scheme 2). ${ }^{6}$ Aryl hydrazides (4), which were either purchased or prepared from aryl ester by substitution with hydrazine, were converted to aryl hydrazine carboxamides (5). Then, they were subsequently cyclized to a series of 5-aryltriazolones (1) in $1.0 \mathrm{~N}$ aq. $\mathrm{NaOH}$ solution. Aryl hydrazine carboxamides (5) were precipitated from the reaction mixture as the reaction proceeded and aryltriazolones (1) were also precipitated when neutralized with acid after the reaction was completed. Isolation of the product in each step by simple filtration greatly streamlined the whole process and made possible a large scale synthesis ( $\mathrm{ca} .10 \mathrm{~g}$ ) of a series of aryltriazolones (1a-1f) in a short period of time.

With aryltriazolones (1) in hand, we explored the regioselective $N$-arylation. We envisioned that subtle stereoelectronic and steric differences between the two reactive nitrogens $(\mathrm{N}-2$ and $\mathrm{N}-4$ ) in the triazolones ${ }^{7}$ can be used as a handle for the regioselective arylation by proper choice of reaction conditions. Although both palladium and copper are well-known transition metals for C-N cross-coupling reactions, ${ }^{8,9}$ copper was found to be more effective in the triazolone systems after our preliminary screening. The initial attempts utilizing catalytic $\mathrm{CuI}, N, N^{\prime}$-dimethylethylenediamine and $\mathrm{K}_{2} \mathrm{CO}_{3}$ in dioxane revealed that 


$$
\text { (c) }
$$$$
\begin{gathered}
\stackrel{\mathrm{NaOCN}}{\mathrm{Nat.} \mathrm{AcOH}} \\
\stackrel{\mathrm{CHCl}}{\mathrm{CH}} \\
50^{\circ} \mathrm{C} \\
92-99 \%
\end{gathered}
$$

$1 \mathrm{a}$

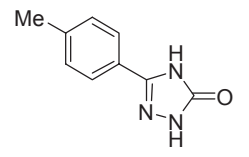

$1 b$<smiles>Cc1cccc(-c2n[nH]c(=O)[nH]2)c1</smiles>

$1 \mathrm{c}$<smiles>NC(=O)NNC(=O)c1cc#[Y]cc1</smiles>

5

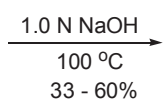<smiles>[X]c1ccc(-c2n[nH]c(=O)[nH]2)cc1</smiles>

1

Scheme 2. Synthesis of aryltriazolones

Table 1. $N$-Arylation of aryltriazolone 1a with $p$-toluic iodide ${ }^{a}$<smiles>O=c1[nH]nc(-c2ccccc2)[nH]1</smiles>

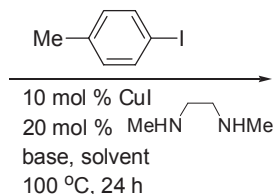

$1 a$

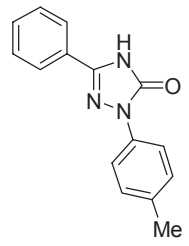

$3 a$

\begin{tabular}{cccc}
\hline Entry & Base & Solvent & Yield $^{b}$ \\
\hline 1 & $\mathrm{~K}_{2} \mathrm{CO}_{3}$ & Dioxane & $5 \%$ \\
2 & $t-\mathrm{BuOK}_{3}$ & Dioxane & $3 \%$ \\
3 & $\mathrm{~K}_{3} \mathrm{PO}_{4}$ & Dioxane & $20 \%$ \\
4 & $\mathrm{Cs}_{2} \mathrm{CO}_{3}$ & Dioxane & $14 \%$ \\
5 & $\mathrm{~K}_{2} \mathrm{CO}_{3}$ & $t$-BuOH & $1 \%$ \\
6 & $\mathrm{~K}_{2} \mathrm{CO}_{3}$ & Toluene & $19 \%$ \\
7 & $\mathrm{~K}_{2} \mathrm{CO}_{3}$ & NMP & $37 \%$ \\
8 & $\mathrm{~K}_{2} \mathrm{CO}_{3}$ & DMSO & $55 \%$ \\
9 & $\mathrm{~K}_{2} \mathrm{CO}_{3}$ & DMF & $63 \%$
\end{tabular}

${ }^{a}$ Reaction conditions: $p$-toluic iodide ( 2.0 equiv), $\mathrm{CuI} \mathrm{(10} \mathrm{mol} \mathrm{\%} \mathrm{equiv),}$ $N, N$-dimethylethylenediamine ( $20 \mathrm{~mol} \%$ equiv), base (3.0 equiv), solvent $1.0 \mathrm{~mL} .{ }^{b}$ Yield determined by HPLC.

the coupling reaction of arytriazolone 1a and $p$-toluic iodide gave $\mathrm{N}$-2-arylated product with less than $10 \%$ conversion. Similar results were observed when various bases and solvents were tested (Table 1); $N$-2-arylated product 3 a was exclusively formed while $\mathrm{N}$-4-arylated product $\mathbf{2}$ a was rarely found. ${ }^{10}$

However, the unsatisfactory yields suggested that the initial reaction conditions suffer from low catalytic activity. In order to search for more reactive catalytic systems which still need to be regioselective, we screened various $\mathrm{Cu}$-catalyzed $\mathrm{C}-\mathrm{N}$ crosscoupling systems including several ligands, bases, and solvents, and their combinations (Table 2). Then, we found that use of trans- $N, N$-dimethylcyclohexane-1,2-diamine as the ligand was the key to success. Switching the ligand to trans- $N, N^{\prime}$-dimethylcyclohexane-1,2-diamine greatly improved the reaction yields. This is also consistent with the fact that trans- $N, N^{\prime}$-dimethylcyclohexane-1,2-diamine is a more reactive ligand than $N, N^{\prime}$ dimethylethylenediamine. ${ }^{11}$ While the choice of bases among $\mathrm{K}_{2} \mathrm{CO}_{3}, \mathrm{~K}_{3} \mathrm{PO}_{4}$, and $\mathrm{Cs}_{2} \mathrm{CO}_{3}$ was not critical, employing polar solvents such as DMF and DMSO was crucial; the use of toluene or dioxane led to a slower reaction rate even at an elevated

Table 2. Optimization of $N$-arylation of aryltriazolone $1 \mathbf{a}^{a}$

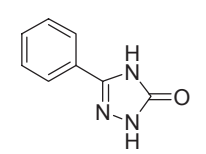

\begin{tabular}{|c|c|c|c|c|}
\hline Entry & Ligand & Base & Solvent & Yield $^{b}$ \\
\hline 1 & & $\mathrm{~K}_{2} \mathrm{CO}_{3}$ & DMF & $97 \%$ \\
\hline 2 & & $\mathrm{~K}_{2} \mathrm{CO}_{3}$ & DMSO & $97 \%$ \\
\hline 3 & $\mathrm{NHMe}$ & $\mathrm{K}_{2} \mathrm{CO}_{3}$ & Toluene & $25 \%$ \\
\hline 4 & & $\mathrm{~K}_{3} \mathrm{PO}_{4}$ & Dioxane & $38 \%$ \\
\hline 5 & & $\mathrm{~K}_{2} \mathrm{CO}_{3}$ & DMSO & $45 \%$ \\
\hline 6 & $\mathrm{OH}$ & $\mathrm{K}_{2} \mathrm{CO}_{3}$ & DMF & $45 \%$ \\
\hline 7 & & $\mathrm{~K}_{2} \mathrm{CO}_{3}$ & DMSO & $43 \%$ \\
\hline 8 & & $\mathrm{~K}_{2} \mathrm{CO}_{3}$ & DMF & $16 \%$ \\
\hline 9 & & $\mathrm{~K}_{2} \mathrm{CO}_{3}$ & DMSO & $55 \%$ \\
\hline 10 & & $\mathrm{~K}_{2} \mathrm{CO}_{3}$ & DMF & $69 \%$ \\
\hline
\end{tabular}

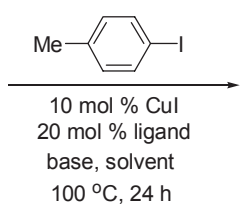

$1 a$

${ }^{a}$ Reaction conditions: $p$-toluic iodide ( 2.0 equiv), $\mathrm{CuI}$ (10 mol \% equiv), ligand ( $20 \mathrm{~mol} \%$ equiv), base (3.0 equiv), solvent $1.0 \mathrm{~mL}$. ${ }^{b}$ Yield determined by HPLC.

temperature. The poor yield seems to be partially due to low solubility of the reactants in these solvents. Either lesser amount of catalyst loading or lower reaction temperature resulted in an incomplete reaction. Thus, after screening with aryltriazolone 1a, we established the optimal reaction conditions, which use $\mathrm{CuI}$ as the catalyst, trans- $N, N^{\prime}$-dimethylcyclohexane-1,2-diamine as the ligand, and DMF as the polar aprotic solvent.

The optimized conditions were applied to the aryltriazolones (1a-1f) to afford corresponding 2,5-biaryltriazolones (Table 3). A range of aryl iodides, including electron-neutral (Table 3 , entries 12, 16, and 20), electron-rich (entries 1, 2, 5, 6, 9, 13, 14, and 17), and electron-poor (entries 3, 4, 7, 8, 10, 11, 15, 18, 19, and 21) aryl iodides, were reacted with aryltriazolones under the conditions to afford 2,5-biaryltriazolones regioselectively in good to excellent yields. Functional groups such as carboxylic ester and nitrile were compatible under the reaction conditions, which would not survive under traditional cyclization condi- 
Table 3. Synthesis of a variety of 2,5-biaryltriazolones via regioselective $N$-arylation of aryltriazolones ${ }^{a}$

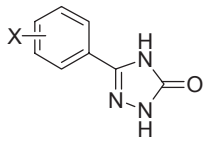

1

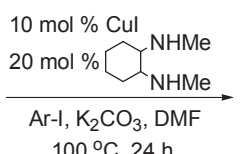

$100^{\circ} \mathrm{C}, 24 \mathrm{~h}$

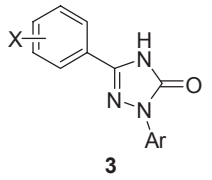

(1)

${ }^{a}$ Reaction conditions: aryl iodide ( 2.0 equiv), CuI ( 10 mol \% equiv), trans$N, N^{\prime}$-dimethylcyclohexane-1,2-diamine (20 mol \% equiv), $\mathrm{K}_{2} \mathrm{CO}_{3}(3.0$ equiv), DMF $1.0 \mathrm{~mL}$. ${ }^{b}$ Isolated yields of $>95 \%$ purity as determined by HPLC and ${ }^{1} \mathrm{H}-\mathrm{NMR}$. tions. ${ }^{2,4}$ In most cases, very little amount of 4,5-biaryl-triazolones were formed, which was determined by LC-MS analysis. As the isolation yields in Table 3 suggested, even in the case of contamination with $N$-4-arylated product up to $5 \%$, it was easily removed by recrystallization from the reaction mixture. Incidentally, we found that methoxyaryl iodides such as 3- and 4-iodoanisole are less effective reactants than other aryl iodides, showing the lower reaction yields (Table 3, entries 2, 6, 9, and 14). The lower yields are due to the formation of unknown sideproducts which are not the $\mathrm{N}$-4-arylated regioisomers. Orthosubstituted aryl ioides gave less than $10 \%$ of the desired products under these conditions; attempts to couple them by extending the reaction time or elevating reaction temperature caused the decomposition of aryltriazolones (1). Although NH-site having more acidic proton can be preferably arylated, ${ }^{7,12}$ the selectivity of the $N$-arylation process appears to be largely controlled by steric factors under these conditions. Thus, all the aryl iodides, which are believed to be readily added to the copper-substrate complex, undergo the reaction at the kinetically favored $\mathrm{N}-2$ position. We are currently testing various aryl iodides under the reaction conditions to see how they affect the selectivity so that we can gain an insight on the mechanism of the crosscoupling reaction.

In summary, we have developed a novel approach to the selective synthesis of 2,5-biaryltriazolones, which are important structures present in biologically active compounds. Aryltriazolones, which are the precursors for biaryltrizolones, were prepared in a straightforward manner from commercially available compounds at large scales. Then, a range of aryl groups were introduced regioselectively to the aryltriazolones via copper-catalyzed C-N cross-coupling reactions. This new method provides an efficient means to access a variety of 2,5-biaryl1,2,4-triazol-3-ones that are not trivial to prepare via other methods.

\section{Experimental Section}

Representative procedure for $\mathrm{N}$-arylation. To a suspension of aryltriazolone (0.5 mmol), $\mathrm{CuI}(9.5 \mathrm{mg}, 0.05 \mathrm{mmol})$ and $\mathrm{K}_{2} \mathrm{CO}_{3}(207 \mathrm{mg}, 1.5 \mathrm{mmol})$ in anhydrous DMF $(1.0 \mathrm{~mL})$ under $\mathrm{N}_{2}$ was added aryl iodide $(1.0 \mathrm{mmol})$ followed by trans $-N, N^{\prime}-$ dimethylcyclohexane-1,2-diamine $(13 \mu \mathrm{L}, 0.1 \mathrm{mmol})$ and the reaction mixture was stirred at $100{ }^{\circ} \mathrm{C}$ for $24 \mathrm{~h}$. The reaction mixture was cooled to room temperature, quenched with water $(10 \mathrm{~mL})$ and extracted with ethyl acetate $(30 \mathrm{~mL} \times 3)$. The combined organic layer was washed with water, brine, dried over $\mathrm{MgSO}_{4}$, and the solvent was evaporated under vacuum. The crude product was recrystallized from ethyl acetate or purified by flash column chromatography ( $n$-hexane:ethyl acetate).

Acknowledgments. We are grateful to the National Research Foundation of Korea (KRF-2008-331-C00167) for financial support of this research. We want to thank Young Jae Kim for contribution to this work.

\section{References}

1. (a) Heers, J.; Back, J. J.; Cutsem, J. V. J. Med. Chem. 1984, 27 , 894. (b) Mullican, M. D.; Wilson, M. W.; Connor, D. T.; Kostlan, 
C. R.; Schrier, D. J.; Dyer, D. D. J. Med. Chem. 1993, 36, 1090. (c) Neslihan, D.; Reyhan, U.; Ahmet, D. Bioorg. Med. Chem. 2002, 10, 3717. (d) Xu, Y.; Mayhugh, D.; Saeed, A.; Wang, X.; Thompson, R. C.; Dominianni, S. J.; Kauffman, R. F.; Sing, J.; Bean, J. S.; Bensch, W. R.; Barr, R. J.; Osborne, J.; Montrose-Rafizadeh, C.; Zink, R. W.; Yumibe, N. P.; Huang, N.; Luffer-Atllas, D.; Rungta, D.; Maise, D. E.; Mantlo, N. B. J. Med. Chem. 2003, 46, 5121. (e) Cowden, C. J.; Wison, R. D.; Bishop, B. C.; Cottrell, I. F.; Davies, A. J.; Dollong, U. Tetrahedron Lett. 2000, 41, 8661.

2. (a) Romine, J. L.; Martin, S. W.; Meanwell, N. A.; Gribkoff, V. K.; Boissard, C. G.; Dworetzky, S. I.; Natale, J.; Moon, S.; Ortiz, A.; Yeleswaram, S.; Pajor, L.; Gao, Q.; Starrett, J. E., Jr. J. Med. Chem. 2007, 50, 528. (b) Romine, J. L.; Martin, S. W.; Gribkoff, V. K.; Boissard, C. G.; Dworetzky, S. I.; Natale, J.; Li, Y.; Gao, Q.; Meanwell, N. A.; Starrett, J. E., Jr. J. Med. Chem. 2002, 45, 2942. (c) Hewawasam, P.; Erway, M.; Thalody, G.; Weiner, H.; Boissard, C. G.; Gribkoff, V. K.; Meanwell, N. A.; Lodge, N.; Starrett, J. E., Jr. Bioorg. Med. Chem. Lett. 2002, 12, 1117.

3. (a) Ying, W.; Przewloka, T.; Chae, J.; Zhang, S.; Li, H.; Du, Z.; James, D.; Chimmanamada, D. U.; Ng, H. P.; Foley, K.; Demko, Z.; Sun, L.; Zhou, D.; Qin, S. U.S. Patent 20080176840, 2008. (b) Lee, C.; James, D.; Zhang, S.; Ying, W.; Chimmanamada, D.; Chae, J.; Przewloka, T. U.S. Patent 20080125587, 2008. (c) Chae, J.; Demko, Z.; Ying, W.; Du, Z.; Foley, K.; James, D.; Ptzewloka, T.; Song, M.; Zhang, S.; Ng, H. P.; Li, H.; Chimmanamada, D. U.; Zhou, D.; Qin, S.; Lee, C.; Sun, L.; Koya, K. U.S. Patent 2008090887, 2008.

4. (a) Ohsumi, K.; Hatanaka, T.; Fujita, K.; Nakagawa, R.; Fukuda, Y.; Nihei, Y.; Suga, Y.; Morinaga, Y.; Akiyama, Y.; Tsuji, T. Bioorg. Med. Chem. Lett. 1998, 8, 3153. (b) Noto, R.; Gruttadauria, M.; Lo Meo, P.; Frenna, V.; Werber, G. J. Heterocyclic Chem. 1995, 32, 1277. (c) Gruttadauria, M.; Buccheri, F.; Cusmano, G.; Lo Meo, P.; Noto, R.; Werber, G. J. Heterocyclic Chem. 1993, 30, 765. (d) Milcent, R.; Nguyen, T. H. J. Heterocyclic Chem. 1986,
23, 881. (e) Nguyen, T. H.; Milcent, R.; Barbier, G. J. Heterocyclic Chem. 1985, 22, 1383.

5. Deng, J. Z.; Burgey, C. S. Tetrahedron Lett. 2005, 46, 7993.

6. (a) Lin, S.; Liu, S. X.; Huang, J. Q.; Lin, C. C. J. Chem. Soc. Dalton Trans. 2002, 8, 1595. (b) Mazzone, G.; Puglisi, G.; Corsaro, A.; Panico, A.; Bonina, F.; Amico-Roxas, M.; Caruso, A.; Trombadore, S. Eur. J. Med. Chem. 1986, 21, 277. (c) George, B.; Papadopoulos, E. P. J. Org. Chem. 1976, 41, 3233.

7. N-4 position is more sterically hindered than $\mathrm{N}-2$ position. $\mathrm{p} K_{\mathrm{a}}$ 's of protons at N-2 and N-4 of aryltriazolone 1a were calculated as 17.1 and 7.5, respectively, using the software ACD (Advanced Chemistry Development)

8. For reviews on palladium-catalyzed cross-coupling reactions, see: (a) Muci, A. R.; Buchwald, S. L. Top. Curr. Chem. 2002, 219, 131. (b) Jiang, L.; Buchwald, S. L. In Metal-Catalyzed CrossCoupling Reactions, 2nd ed.; de Meijere, A., Diederich, F., Eds.; John Wiley \& Sons: Weinheim, 2004; p 699. (c) Christmann, U.; Vilar, R. Angew. Chem. Int. Ed. 2005, 44, 366.

9. For reviews on copper-catalyzed cross-coupling reactions, see: (a) Ley, S. V.; Thomas, A. W. Angew. Chem., Int. Ed. 2003, 42, 5400. (b) Kunz, K.; Scholz, U.; Ganzer, D. Synlett. 2003, 2428. (c) Beletskaya, I. P.; Cheprakov, A. V. Coord. Chem. Rev. 2004, $248,2337$.

10. Two regioisomers (2a and $\mathbf{3 a}$ ) were synthesized according to the previously reported methods (see ref 2 ). The major product of the $\mathrm{N}$-arylation reaction was compared with these authentic regioisomers via TLC, LC-MS, and NMR analysis, and was confirmed as $\mathrm{N}$-2-arylated product $\mathbf{3 a}$.

11. Klapars, A.; Huang, X.; Buchwald, S. L. J. Am. Chem. Soc. 2002 , $124,7421$.

12. (a) Wolter, M.; Klapars, A.; Buchwald, S. L. Org. Lett. 2001, 3, 3803. (b) Chae, J.; Buchwald, S. L. J. Org. Chem. 2004, 69, 3336. (c) Wang, Z.; Skerlj, R. T.; Bridger, G. J. Tetrahedron Lett. 1999, 40,3543. 